\title{
Erratum to: Exploration of gold at the east end of Wadi Allaqi, South Eastern Desert, Egypt, using remote sensing techniques
}

\author{
Salem M. Salem ${ }^{1}$ N. M. Soliman ${ }^{1}$
}

Published online: 17 September 2015

(C) Saudi Society for Geosciences 2015

Erratum to: Arab J Geosci

DOI 10.1007/s12517-015-1880-x

The original version of this article, unfortunately, contained errors.

The images of Figures 8 and 10 were incorrect. The correct images are given in this article.

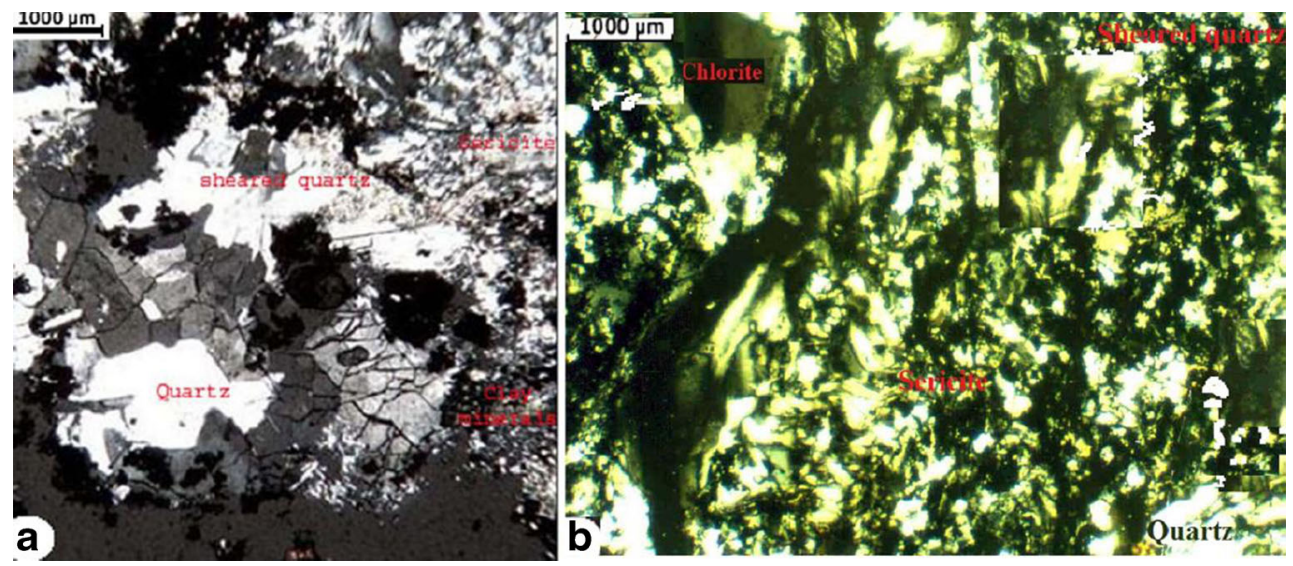

The online version of the original article can be found at http://dx.doi.org/ 10.1007/s12517-015-1880-x.

\footnotetext{
Salem M. Salem

salem_moher@hotmail.com

1 National Authority for Remote Sensing and Space Sciences

(NARSS), Cairo, Egypt
} 

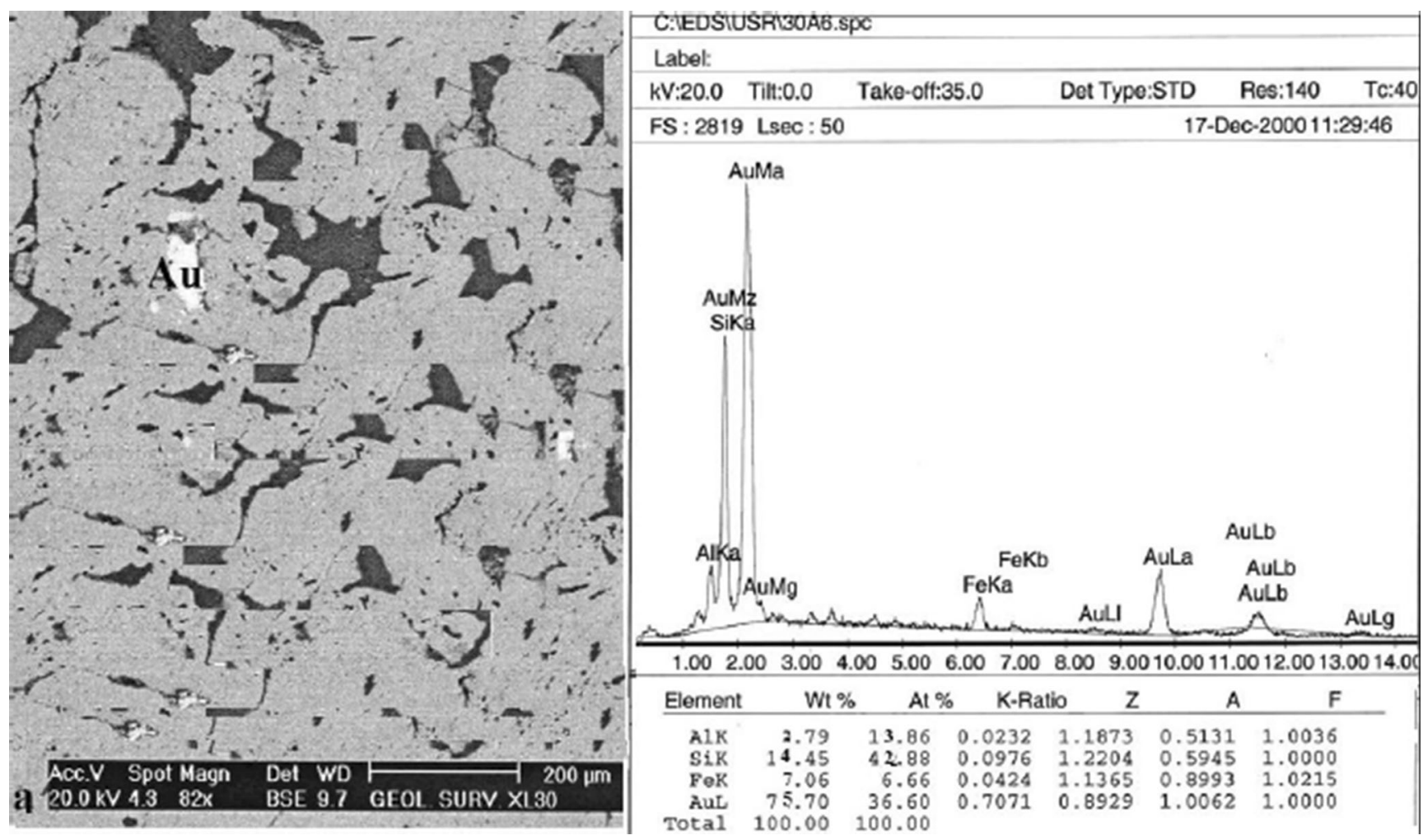